\title{
Bear, bull, sidewalk, and crash: the evolution of the US stock market using over a century of daily data
}

Article

Accepted Version

Creative Commons: Attribution-Noncommercial-No Derivative Works 4.0

Wang, S. ORCID: https://orcid.org/0000-0003-2113-5521, Rangan, G. and Yue-Jun, Z. (2021) Bear, bull, sidewalk, and crash: the evolution of the US stock market using over a century of daily data. Finance Research Letters, 43. 101998. ISSN 1544-6123 doi: https://doi.org/10.1016/j.frl.2021.101998 Available at https://centaur.reading.ac.uk/96553/

It is advisable to refer to the publisher's version if you intend to cite from the work. See Guidance on citing.

To link to this article DOI: http://dx.doi.org/10.1016/j.frl.2021.101998

Publisher: Elsevier

All outputs in CentAUR are protected by Intellectual Property Rights law, including copyright law. Copyright and IPR is retained by the creators or other copyright holders. Terms and conditions for use of this material are defined in the End User Agreement.

www.reading.ac.uk/centaur 
Central Archive at the University of Reading

Reading's research outputs online 


\title{
Bear, Bull, Sidewalk, and Crash: The Evolution of the US Stock Market Using Over a Century of Daily Data ${ }^{\#}$
}

\begin{abstract}
In this paper, we employ a four-state hidden semi-Markov model, which outperforms a hidden Markov model, to identify market conditions of the US stock market over the daily period from $16^{\text {th }}$ of February, 1885 to $4^{\text {th }}$ of June, 2020. Our results indicate that the four hidden states represent bear-, bull-, sidewalk-, and crash-markets, which in turn appropriately capture the various major historical events during the period of study.
\end{abstract}

Keywords: Dow Jones Industrial Average, Hidden (semi-)Markov Models, Stock Returns, Market Conditions

JEL Codes: C22, G10

\section{Introduction}

Historically, the stock market of the United States (US) has been identified as a leading indicator for major macroeconomic variables, like metrics of economic activity, inflation and interest rates (Stock and Watson, 2003; Simo-Kengne et al., 2016; Plakandaras, 2017; Pierdzioch and Gupta, 2020). Naturally, appropriate modeling of the states of the equity market is of paramount importance for policymakers, as well as investors, especially at high-frequency. This is because, one can then use this information in mixed frequency data sampling (MIDAS) models to produce nowcasts and real-time predictions of the variables that are sampled at lower (monthly or quarterly) frequencies, such as output growth and inflation (Andreou et al., 2013; Breitung and Roling, 2015). Against this backdrop, we aim to identify the evolution of the market conditions of the daily returns of Dow Jones Industrial Average (DJIA) over its entire available history covering the period from $16^{\text {th }}$ of February, 1885 to $4^{\text {th }}$ of June, 2020. The DJIA time series data is employed due to the large number of observations available, which in turn allows us to avoid incorrect inference due to sub-sample-specific characteristics or inefficiency of estimates obtained from small samples, as stressed by Gebka and Wohar (2019). Note that these authors analysed the predictive power of the DJIA index returns, measured at different quantiles of its distribution, for future return distribution for the period of $26^{\text {th }}$ May, 1896 to $10^{\text {th }}$ September, 2014, i.e., over a similar historical sample like ours.

Market conditions have been studied mostly with Markov-switching techniques (e.g. see, Babalos et al., 2015). One interesting insight from the Markov-switching models is the number of time-periods that a market condition can last before it transits to another, with this time interval typically referred to as sojourn time. ${ }^{1}$ However, one limitation of Markov-switching models is that the distribution of sojourn time can only implicitly follow a geometric distribution, which sometimes may not fit financial returns well (Bulla and Bulla, 2006). As an extension of the classical Hidden Markov model (HMM), the hidden semi-Markov model (HSMM) can arbitrarily specify the sojourn time distribution. Given this, Bulla and Bulla (2006) show that the HSMM outperforms the HMM in the reproduction of the stylized facts of daily financial returns. Since then, the HSMM has been a prevailing tool to quantitively identify the market conditions based on the distributional properties of the hidden states (Lau et al., 2017;

\footnotetext{
\# We would like to thank an anonymous referee for many helpful comments. However, any remaining errors are solely ours.

${ }^{1}$ In the literature, sojourn time is also known as duration time, occupancy time, and dwell time.
} 
Liu and Wang, 2017a; Liu and Wang, 2017b; Apergis et al., 2019). We refer the reader to $\mathrm{Yu}$ (2010) for detailed literature reviews on the HSMM and alternative applications in this regard. In light of this, we also employ the HSMM model, for the first time in the literature, to analyze and identify hidden states of the DJIA returns, since its inception spanning 136 years of daily data. The remainder of the paper is organized as follows: Section 2 outlines the methodology, while Section 3 discusses the data and the empirical results, with Section 4 concluding the paper.

\section{Methodology}

The HSMM is based on two coupled processes, the state process $\left\{S_{t}\right\}_{t=1}^{T}$ and the observation process $\left\{X_{t}\right\}_{t=1}^{T}$. The state process follows a semi-Markov chain ${ }^{2}$, which is constructed by an embedded first-order Markov chain with sojourn time distribution. $\left\{S_{t}\right\}_{t=1}^{T}$ is hidden and unobservable, and can only take finite state space, i.e. $S_{t} \in\{1,2, \ldots, K\}$. The time series dependence of $S_{t}$ is characterized by the transition probabilities defined in Equation (1):

$$
\gamma_{i, j}=P\left(S_{t+1}=j \mid S_{t+1} \neq i, S_{t}=i\right) \text { with } \sum_{j \neq i} \gamma_{i, j}=1 \text { and } \gamma_{i, i}=0 \text {. }
$$

Arranging all possible transition probabilities together into a matrix produces the transition probability matrix (TPM) with $K \times K$ dimension. It should be noted that the diagonal entries in the TPM of HSMM are all zero.

Recall that the HMM can only have a geometric distribution for its sojourn time. Unlike the HMM, the sojourn time in the HSMM,

$$
d_{j}(\tau)=P\left(S_{t+\tau+1} \neq j, S_{t+\tau-v}=j, v=0, \ldots, \tau-2 \mid S_{t+1}=j, S_{t} \neq j\right),
$$

can be controlled by any arbitrary distribution, as shown in Equation (2). Thus, the number of periods for the HSMM staying in a hidden state can be more flexible.

The observation process $\left\{X_{t}\right\}_{t=1}^{T}$ is observable, and is generated based on the state process $\left\{S_{t}\right\}_{t=1}^{T}$. Importantly, the observation at time $t$ only depends on the state at time $t$ via the component distribution, as indicated in Equation (3):

$$
b_{j}\left(x_{t}\right)=P\left(X_{t}=x_{t} \mid S_{t}=j\right) .
$$

Bulla and Bulla (2006) provide the likelihood function for the observations modelled by the HSMM. Then the expectation-maximization (EM) algorithm (Baum et al., 1970) is used to estimate the model parameters in the HSMM. Based on the estimated parameters, the unobservable state process can be globally decoded by the Viterbi algorithm (Viterbi, 1967), which enable us to reveal the timing and the evolvement of the hidden states over the sample period. For practical settings, we follow Liu and Wang (2017a) to use the logarithmic distribution for the sojourn time distribution and the normal distribution for the component distribution, since they are straightforward to interpret, and the fact that convergence in the EM algorithm can be reached in general.

\footnotetext{
${ }^{2}$ Only non-absorbing states are considered in this study. Additionally, we follow Bulla and Bulla (2006) to consider the right-censored HSMM, which does not require the assumption that last observation coincide with the exit of a state.
} 


\section{Data and Empirical Results}

Our analysis involves the log-returns of the DJIA over the daily period from $16^{\text {th }}$ of February, 1885 to $4^{\text {th }}$ of June, 2020, with the start and end dates being governed by the availability of data at the time of writing this paper. The data is sourced from MeasuringWorth: https://www.measuringworth.com/datasets/DJA/index.php. We first present the model comparison of the HSMM and the HMM with different numbers of hidden states in Table 1. The four-state HSMM provides the best fit in terms of log likelihood, and is also the best model according to the principles of Akaike Information Criterion (AIC) and Bayesian Information Criterion (BIC). We will proceed with this best model, i.e., the four-state HSMM, for the remainder of our analysis.

Table 1. Model Comparison

\begin{tabular}{lccc}
\hline \hline & Log Likelihood & AIC & BIC \\
\hline 2-State HSMM & -47747.15 & 95508.30 & 95567.93 \\
3-State HSMM & -46666.82 & 93361.63 & 93480.91 \\
4-State HSMM & -46356.25 & $\mathbf{9 2 7 5 8 . 4 9}$ & $\mathbf{9 2 9 5 4 . 4 4}$ \\
2-State HMM & -47989.73 & 95993.45 & 96053.09 \\
3-State HMM & -46739.19 & 93506.39 & 93625.66 \\
4-State HMM & -46388.95 & 92823.90 & 93019.85 \\
\hline \hline
\end{tabular}

Note: The red bold number indicates the best metric for the criteria of model comparison.

Next, Table 2 shows the estimation results of the four-state HSMM. State 1 can be interpreted as the crash-market because it has an extreme negative mean $(-0.320)$ and the largest standard deviation (3.423), which typically covers the left tail of the return distribution. State 2 is characterized by a negative mean (-0.069) and second largest standard deviation (1.467), and thus corresponds to the bear-market. State 3 has a positive mean (0.072) and the lowest standard deviation (0.489), which meets distributional properties of the bull-market. Lastly, State 4 has a mean insignificantly different from zero (t-statistic: 1.147) and the second lowest standard deviation (0.872), thus capturing the sidewalk-market. The information on sojourn time confirms our interpretation: the crash-market is typically short-lived with average sojourn time of 31 days, and the bear-market lasts slightly longer with 52 days on average, while the bull and the sidewalk markets tend to continue for over half a year (125 days). We have four observations by examining the TPM: 1) the bear-market always follows after the crash; 2) the bear-market can transit to the sidewalk-market (68.9\%) and to the crash-market (31.1\%), but it never directly evolves into the bull-market; 3 ) the bull-market is succeeded by the sidewalkmarket with a probability of $99.2 \%$; and 4) the sidewalk-market is more likely to be followed by the bull-market $(81.2 \%)$, rather than the bear-market (18.8\%).

Comparing with the existing relevant literature, our results in Table 2 provide some new insights. First, Liu and Wang (2017a, 2017b) only find three market conditions (bear, bull, and sidewalk), which is mainly due to the relatively shorter length of the sample periods in their studies. However, by using over a century of daily data, we find an additional market condition, namely the crash market, which has extremely negative mean and substantially large standard deviation. Second, although our estimation results on the bear-, bull-, and sidewalk-markets in the US are generally consistent with Liu and Wang (2017b), their study shows that the bear market is almost certain to be move to the sidewalk-market, while we find that the bear-market can also be transited to the crash-market. Third, the average sojourn time of the bear-, the bull-, and the sidewalk-markets in our estimation are modestly longer than those in Liu and Wang (2017b) 
Table 2. Estimation of the Four-State HSMM

\begin{tabular}{clrrrr}
\hline \hline & & State 1 & State 2 & State 3 & State 4 \\
\hline \multirow{2}{*}{$\begin{array}{c}\text { Conditional } \\
\text { Distribution }\end{array}$} & Mean & -0.320 & -0.069 & 0.072 & 0.028 \\
& SD & 3.423 & 1.467 & 0.489 & 0.872 \\
& -statistic & -3.183 & -1.457 & 2.233 & 1.147 \\
\hline \multirow{5}{*}{ From/To } & & & & \\
& State 1 (Crash) & - & $100.0 \%$ & $0.0 \%$ & $0.0 \%$ \\
& State 2 (Bear) & $31.1 \%$ & - & $0.0 \%$ & $68.9 \%$ \\
& State 3 (Bull) & $0.7 \%$ & $0.0 \%$ & - & $99.2 \%$ \\
& State 4 (Sidewalk) & $0.0 \%$ & $18.8 \%$ & $81.2 \%$ & - \\
\hline \multirow{2}{*}{ Sojourn } & No. of Days & 1161 & 5275 & 11191 & 19406 \\
Time & No. of Times & 38 & 102 & 89 & 153 \\
& Average Sojourn Time & 30.553 & 51.716 & 125.742 & 126.837 \\
\hline \hline
\end{tabular}

By employing the Viterbi algorithm (Viterbi, 1967), we can globally decode the timing of the four hidden states over the entire sample period, which in turn is displayed in Figure 1. To facilitate studying the evolution of the states of the market, we collect the information of the four hidden states into different sub-periods based on the well-known historical events, as shown in Table 3. In the $19^{\text {th }}$ century and before World War I (WWI) period, the market was mainly in the bull or sidewalk phases, with some occasional crashes. In course of the WWI, the percentage of periods in the bull-market substantially decreased, while the percentage of other market conditions increased, and in particular the crash episodes. The economy started to recover after the WWI until the "Great Depression" in 1929, during which period there was no crash. Nevertheless, the market was in tremendous turmoil during the "Great Depression" with nine episodes of crashes, and no bull-market at all. Intriguingly, the market experienced a "Uturn" since the start of World War II (WWII), with 1,263 days in the bull-market (out of 1,782 days in total). This can be intuitively explained by the fact that, WWII largely helped the US to boost its economy. Over the long-lasting Cold War, the market had relatively lower percentage of time spent in the bear phase, and modestly higher percentage in the bull-market. In the preGlobal Financial Crisis (GFC) period, the market seemed to be normal with similar pattern as observed in the $19^{\text {th }}$ Century, pre-WWI, and post-WWI. Since then, the market encountered substantial turmoil during the GFC in 2008 (and the associated "Great Recession"), and the European sovereign debt crisis (ESDC) in 2010, featured with 10.2\% of total days in the crashand $32.7 \%$ in the bear-markets. In the recent years, the US stock market had gradual recovery with $51.5 \%$ of total days in the bear phase, until another dramatic shock due to the outbreak of COVID-19.

\section{Conclusion}

In this paper, we employ a HSMM on the DJIA returns covering the period of $16^{\text {th }}$ of February, 1885 to $4^{\text {th }}$ of June, 2020. We find that a four-state HSMM model, with its hidden states corresponding to bear, bull, sidewalk, and crash markets, fits the data the best when compared to the version of the model with two and three hidden states. This model also outperforms the HMM model estimated with the same number of hidden states. Finally, when we analyze the evolution of the returns, our model is appropriately able to associate the four states with the various historical events, such as WWI, the "Great Depression" WWII, the Cold War, global 
financial and European sovereign debt crises, and the recent outbreak of COVID-19. Given that, stock market movements act as the leading indicator for macroeconomic variables measured in lower frequencies, the high-frequency information contained in the hidden states identified by the HSMM model could be used by policymakers to nowcast the economy based on the MIDAS models, and investors to conduct timely portfolio allocations.

Figure 1. Global decoding of the four-State HSMM

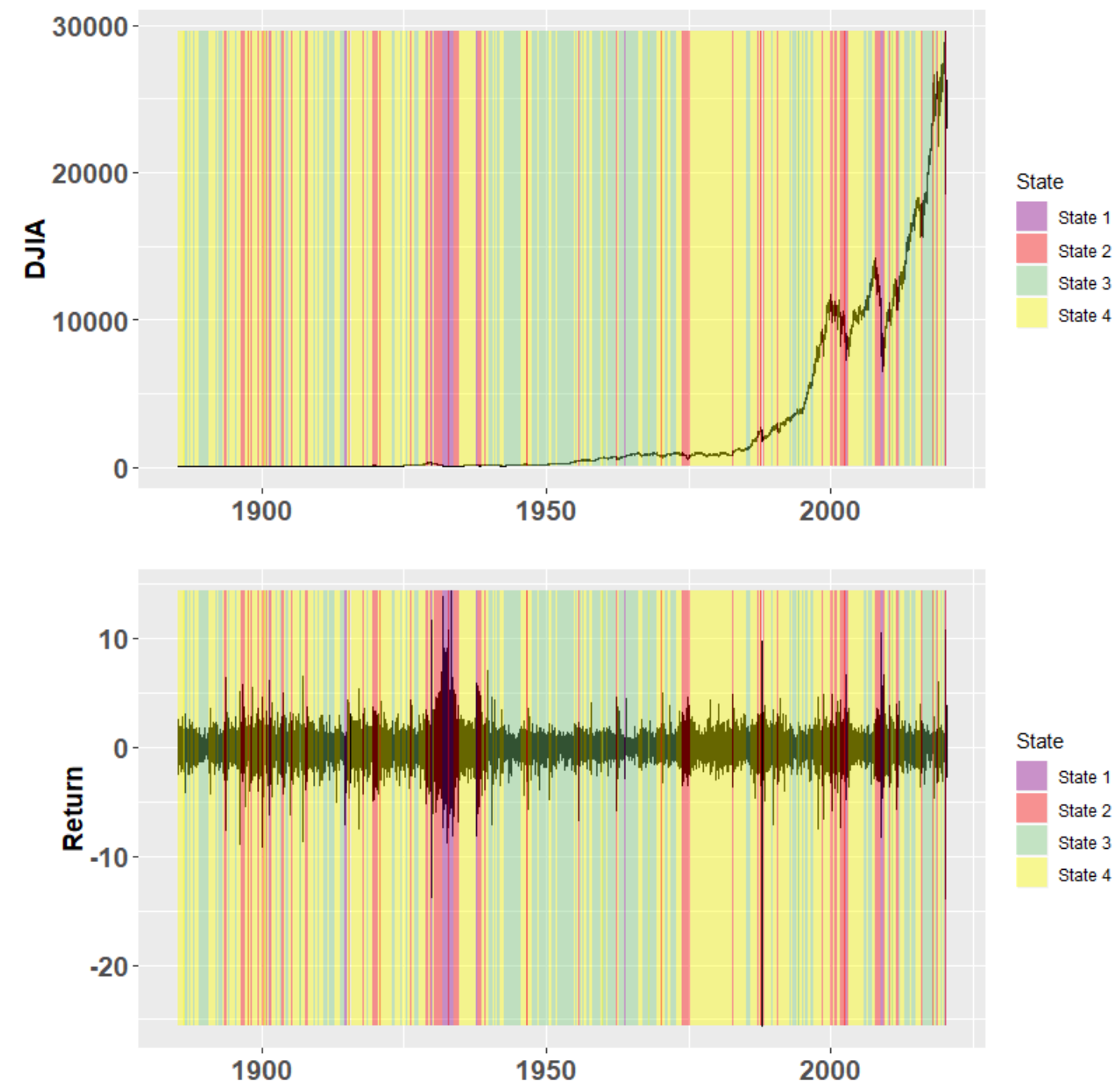

Note: Upper panel: DIJA index along with the four decoded states; Lower panel: returns of DIJA along with the four decoded states. 
Table 3. Information on the Four Hidden States in Different Sub-Periods

\begin{tabular}{|c|c|c|c|c|c|c|c|c|c|c|c|c|c|c|c|}
\hline \multirow{2}{*}{ Famous Event } & \multirow{2}{*}{ Start } & \multirow{2}{*}{ End } & \multirow{2}{*}{ Total Days } & \multicolumn{4}{|c|}{ No. of Days } & \multicolumn{4}{|c|}{ Percentage in Total Days } & \multicolumn{4}{|c|}{ No. of Times } \\
\hline & & & & State 1 & State 2 & State 3 & State 4 & State 1 & State 2 & State 3 & State 4 & State 1 & State 2 & State 3 & State 4 \\
\hline 19 Century & $1885-02-16$ & $1899-12-31$ & 4488 & 37 & 512 & 1302 & 2637 & $0.8 \%$ & $11.4 \%$ & $29.0 \%$ & $58.8 \%$ & 3 & 12 & 9 & 18 \\
\hline Pre-WWI & 1900-01-01 & $1914-07-27$ & 4358 & 29 & 675 & 1146 & 2508 & $0.7 \%$ & $15.5 \%$ & $26.3 \%$ & $57.5 \%$ & 3 & 17 & 14 & 27 \\
\hline WWI & $1914-07-28$ & $1918-11-11$ & 1176 & 30 & 217 & 34 & 895 & $2.6 \%$ & $18.5 \%$ & $2.9 \%$ & $76.1 \%$ & 4 & 8 & 1 & 6 \\
\hline Post-WWI & $1918-11-12$ & 1929-09-03 & 3229 & 0 & 563 & 515 & 2151 & $0.0 \%$ & $17.4 \%$ & $15.9 \%$ & $66.6 \%$ & 0 & 5 & 4 & 9 \\
\hline Great Depression & 1929-09-04 & $1939-08-31$ & 2981 & 791 & 1045 & 0 & 1145 & $26.5 \%$ & $35.1 \%$ & $0.0 \%$ & $38.4 \%$ & 9 & 14 & 0 & 4 \\
\hline Cold War & $1945-08-16$ & $1991-12-26$ & 11878 & 29 & 887 & 4802 & 6160 & $0.2 \%$ & $7.5 \%$ & $40.4 \%$ & $51.9 \%$ & 8 & 21 & 29 & 43 \\
\hline Pre-GFC & $1991-12-27$ & 2007-01-31 & 3804 & 54 & 640 & 941 & 2169 & $1.4 \%$ & $16.8 \%$ & $24.7 \%$ & $57.0 \%$ & 5 & 10 & 9 & 14 \\
\hline GFC and ESDC & 2007-02-01 & $2012-07-31$ & 1386 & 142 & 453 & 205 & 586 & $10.2 \%$ & $32.7 \%$ & $14.8 \%$ & $42.3 \%$ & 2 & 5 & 5 & 8 \\
\hline Recent & 2012-08-01 & 2020-06-04 & 1910 & 36 & 197 & 983 & 694 & $1.9 \%$ & $10.3 \%$ & $51.5 \%$ & $36.3 \%$ & 2 & 8 & 11 & 18 \\
\hline
\end{tabular}

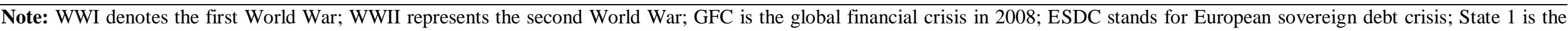
crash-market, State 2 is the bear-market, State 3 is the bull-market, and State 4 is the sidewalk-market. 


\section{References}

Andreou, E., Ghysels, E., and Kourtellos, A. (2013). Should Macroeconomic Forecasters Use Daily Financial Data and How? Journal of Business \& Economic Statistics, 31(2), 240-251.

Apergis, N., Gozgor, G., Lau, C.K.M., and Wang, S. (2019). Decoding the Australian electricity market: new evidence from three-regime hidden semi-Markov model. Energy Economics, 78, 129-142.

Baum, L. E., Petrie, T., Soules, G., and Weiss, N. (1970). A maximization technique occurring in the statistical analysis of probabilistic functions of Markov chains. The Annals of Mathematical Statistics, 41(1), 164-171.

Babalos, V., Balcilar, M., \& Gupta, R. (2015). Herding behavior in real estate markets: novel evidence from a Markov-switching model. Journal of Behavioral and Experimental Finance, 8, 40-43.

Breitung, J., and Roling, C. (2015). Forecasting Inflation Rates Using Daily Data: A Nonparametric MIDAS Approach. Journal of Forecasting, 34(7), 588-603.

Bulla, J., and Bulla, I. (2006). Stylized facts of financial time series and hidden semi-Markov models. Computational Statistics \& Data Analysis, 51(4), 2192-2209.

Gebka, B., and Wohar, M.E. (2019). Stock return distribution and predictability: Evidence from over a century of daily data on the DJIA index. International Review of Economics \& Finance, $60,1-25$.

Lau, C.K.M., Vigne, S.A., Wang, S., and Yarovaya, L. (2017). Return spillovers between white precious metal ETFs: the role of oil, gold, and global equity. International Review of Financial Analysis, 52, 316-332.

Liu, Z., and Wang, S. (2017a). Decoding Chinese stock market returns: Three-state hidden semi-Markov model. Pacific-Basin Finance Journal, 44, 127-149.

Liu, Z., and Wang, S. (2017b). Understanding the Chinese stock market: international comparison and policy implications. Economic and Political Studies, 5(4), 441-455.

Pierdzioch C., and Gupta R. (2020). Uncertainty and Forecasts of U.S. Recessions. Studies in Nonlinear Dynamics \& Econometrics, 24(4), 1-20.

Plakandaras, V., Cunado, J., Gupta, R., and Wohar, M.E. (2017). Do leading indicators forecast U.S. recessions? A nonlinear re-evaluation using historical data. International Finance, 20(3), 289-316.

Simo-Kengne, B.D., Miller, S.M., Gupta, R., and Balcilar, M. (2016). Evolution of the Monetary Transmission Mechanism in the US: the Role of Asset Returns. The Journal of Real Estate Finance and Economics, 52(3), 226-243.

Stock, J.H., and Watson, M.W. (2003). Forecasting Output and Inflation: The Role of Asset Prices. Journal of Economic Literature, 41(3), 788-829.

Viterbi, A. (1967). Error bounds for convolutional codes and an asymptotically optimum decoding algorithm. IEEE transactions on Information Theory, 13(2), 260-269.

Yu, S.Z. (2010). Hidden semi-Markov models. Artificial intelligence, 174(2), 215-243. 